\title{
naw \\ Correlation between Pitch Impregnation Pressure and Pore Sizes of Graphite Block
}

\author{
Changkyu Kim ${ }^{1}$, Woong Kwon ${ }^{1}$, Moon Hee Lee ${ }^{1,2}$, Jong Seok Woo ${ }^{2}$ and Euigyung Jeong ${ }^{1, *(\mathbb{D})}$ \\ 1 Department of Textile System Engineering, Kyungpook National University, Daegu 41566, Korea; \\ se02126000@gmail.com (C.K.); kwoong7242@naver.com (W.K.); moonhee.lee@morganplc.com (M.H.L.) \\ 2 Advanced Center of Engineering, Morgan Advanced Materials, 23, Dalseong2cha 4-ro, Guji-myeon, \\ Dalseong-gun, Daegu 43013, Korea; JustinJongSeok.Woo@morganplc.com \\ * Correspondence: wolfpack@knu.ac.kr
}

Citation: Kim, C.; Kwon, W.; Lee, M.H.; Woo, J.S.; Jeong, E. Correlation between Pitch Impregnation Pressure and Pore Sizes of Graphite Block. Materials 2022, 15, 561. https:// doi.org/10.3390/ma15020561

Academic Editor: Alina Pruna

Received: 23 December 2021

Accepted: 11 January 2022

Published: 12 January 2022

Publisher's Note: MDPI stays neutral with regard to jurisdictional claims in published maps and institutional affiliations.

Copyright: (c) 2022 by the authors. Licensee MDPI, Basel, Switzerland. This article is an open access article distributed under the terms and conditions of the Creative Commons Attribution (CC BY) license (https:// creativecommons.org/licenses/by/ $4.0 /)$.

\begin{abstract}
This study aimed to investigate the effect of impregnation pressure on the decrease in porosity of impregnated bulk graphite. The correlation between pitch impregnation behavior and the pore sizes of the bulk graphite block was studied to determine the optimal impregnation pressure. The densities and porosities of the bulk graphite before and after pitch impregnation under various pressures between 10 and 50 bar were evaluated based on the Archimedes method and a mercury porosimeter. The density increased rates increased by $1.93-2.44 \%$, whereas the impregnation rate calculated from the rate of open porosity decreased by $15.15-24.48 \%$. The density increase rate and impregnation rate were significantly high when the impregnation pressures were 40 and 50 bar. Compared with impregnation pressures of 10, 20, and 30 bar, the minimum impregnatable pore sizes with impregnation pressures of 40 and 50 bar were $30-39$ and $24-31 \mathrm{~nm}$, respectively. The mercury intrusion porosimeter analysis results demonstrated that the pressure-sensitive pore sizes of the graphite blocks were in the range of $100-4500 \mathrm{~nm}$. Furthermore, the ink-bottle-type pores in this range contributed predominantly to the effect of impregnation under pressure, given that the pitch-impregnated-into-ink-bottle-type pores were difficult to elute during carbonization.
\end{abstract}

Keywords: artificial graphite; graphite block; pitch; impregnation; pore properties

\section{Introduction}

Artificial graphite is widely used in various industries due to its high thermal and electrical conductivity, chemical resistance, high mechanical strength, low thermal expansion, excellent thermal shock resistance under rapid temperature changes, de-wetting, selflubrication, air-tightness, and machinability [1-3]. There are two forms of artificial graphite: powder and bulk. Artificial graphite powders, such as graphene and graphite/graphene composites, are used primarily as anode materials for secondary ion batteries (lithium ion, sodium ion, and aluminum ion) and supercapacitors. By contrast, artificial bulk graphite is used in silicon ingots for semiconductors, nuclear reactor moderators, bearings, special machine parts, mechanical seals, cell divider plates, and steel-making electrode bars [4-9].

The general manufacturing process of bulk graphite starts with mixing petroleum- or coal-tar-pitch-derived cokes with a binder pitch or resin. The mixture is then manufactured into bulk graphite through molding, carbonization, impregnation, graphitization, and purification [10-12]. When the molded mixture is carbonized, volatile compounds are released from the pyrolysis or evaporation of a binder pitch or resin components, generating pores with various sizes inside the bulk graphite that degrade the graphite's mechanical, electrical, and thermal properties [12]. Consequently, impregnation followed by heat treatment is required to minimize these pores to produce the desired properties of the bulk graphite.

The viscosity, surface tension, contact angle, and carbon yield during impregnation are crucial for minimizing the porosity of bulk graphite [13-18]. The impregnation conditions, 
such as pressure and temperature profile, are also critical [3,19]. Lee et al. reported that the impregnation of phenol resin increased as its viscosity decreased and that the impregnation was affected by the porosity of the graphite. As the porosity of the graphite increased, the impregnation rate increased $[13,14]$. Although other parameters affect the impregnation of the bulk graphite, related studies are scarce. The impregnation temperature and pressure are of practical relevance because they can influence the economics of impregnation. When higher temperatures and pressures are required, the cost of impregnation dramatically increases.

Accordingly, this study aimed to investigate the effect of impregnation pressure on the decrease in porosity of impregnated bulk graphite. The correlation between the pitch impregnation behaviors and pore sizes of bulk graphite blocks was studied to determine the optimal impregnation pressure. The apparent densities and porosities of the bulk graphite before and after pitch impregnation under various pressures between 10 and 50 bar were evaluated based on the Archimedes method and a mercury porosimeter.

\section{Materials and Methods}

\subsection{Materials}

Coal tar pitch was used as an impregnator and purchased from Ruetgers Germany $\mathrm{GmbH}$ (Castrop-Rauxel, Germany). Bulk graphite blocks were provided by the Morgan Korea company (Daegu, Korea). Diiodomethane (99+\%) was purchased from Acros Organics (Waltham, MA, USA).

\subsection{Characterization of the Impregnation Pitch}

The elemental contents of the impregnation pitch were analyzed using an elemental analyzer (Flash 2000, Thermo Fisher Scientific, Waltham, MA, USA). Carbon yield was measured using thermogravimetric analysis (TGA, Q 500, TA instrument, New Castle, DE, USA) from 25 to $1000{ }^{\circ} \mathrm{C}$ with a heating rate of $5{ }^{\circ} \mathrm{C} / \mathrm{min}$ under a nitrogen atmosphere. The softening point of the impregnation pitch was evaluated based on ASTM D3416 with a heating rate of $2{ }^{\circ} \mathrm{C} / \mathrm{min}$ using a softening point analyzer (DP-70, Mettler Toledo, Columbus, $\mathrm{OH}, \mathrm{USA})$. The contents of the quinoline insoluble were measured based on ASTM D2318, and the contents of toluene insoluble were measured based on ASTM D4312. The properties of the pitch impregnator are presented in Table 1.

Table 1. Impregnation pitch specifications.

\begin{tabular}{cc}
\hline $\mathrm{C}(\%)$ & 91.87 \\
\hline $\mathrm{H}(\%)$ & 4.53 \\
\hline $\mathrm{N}(\%)$ & 1.24 \\
\hline $\mathrm{O}(\%)$ & 1.36 \\
\hline $\mathrm{S}(\%)$ & 0.64 \\
\hline Carbon yield $(\%)$ & 39.12 \\
\hline Softening point $\left({ }^{\circ} \mathrm{C}\right)$ & 90.00 \\
\hline Quinoline insoluble contents $(\%)$ & 3.04 \\
\hline Quinoline soluble, Toluene insoluble contents $(\%)$ & 18.06 \\
\hline Toluene soluble contents $(\%)$ & 78.87 \\
\hline
\end{tabular}

\subsection{Impregnation of Bulk Graphite Block}

Graphite blocks were dried at $110^{\circ} \mathrm{C}$ for $8 \mathrm{~h}$ in a convection oven before impregnation. The dried block and pitch were placed in the reactor of the impregnating apparatus, and the reactor was vacuumed for $30 \mathrm{~min}$ to remove any residual water vapor inside the graphite block and pitch. The reactor was then heated to $110^{\circ} \mathrm{C}$ to melt the pitch, and the designated pressure was applied for impregnation of the pitch into the graphite blocks. The pressures 
used in the impregnation were 10, 20,30,40, and 50 bar. This condition was maintained for $1 \mathrm{~h}$, and the reactor was cooled and depressurized to room temperature and pressure. The impregnated block was removed from the reactor and carbonized at $1000{ }^{\circ} \mathrm{C}$ for $1 \mathrm{~h}$. After carbonization of the impregnated block, the eluted pitch on the surface of the graphite block was removed using a grinder. Figure 1 illustrates a schematic of the impregnation apparatus.

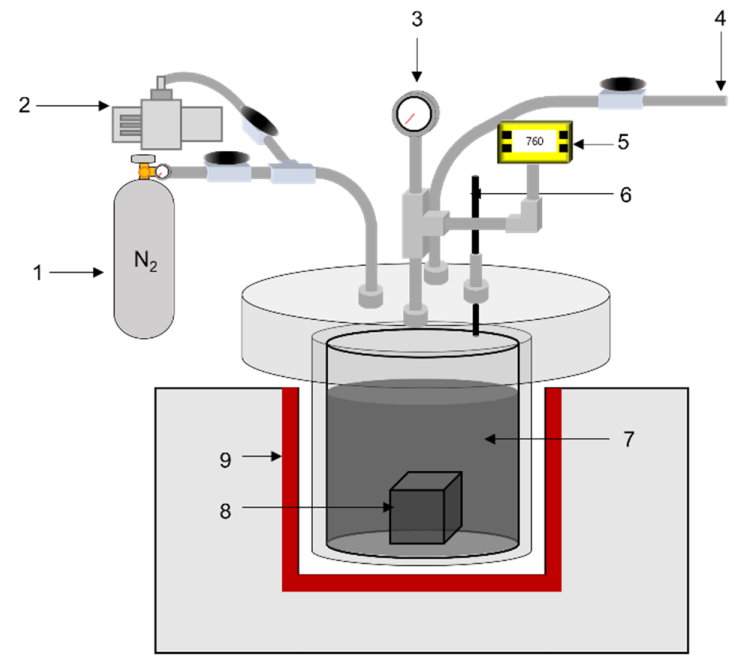

Figure 1. Schematic of impregnation apparatus. (1) $\mathrm{N}_{2}$ gas, (2) vacuum motor, (3) pressure gauge, (4) gas outlet, (5) vacuum gauge, (6) thermocouple, (7) pitch, (8) graphite block, (9) heating element.

\subsection{Density, Porosity, and Impregnation Rate Measurements}

Changes in the densities and porosities of the graphite blocks were measured using the Archimedes method based on ASTM C20 [20]. The impregnation rates of the blocks at various pressures were calculated using Equation (1).

$$
\text { Impregnation rate }(\%)=\frac{P-P_{0}}{P_{0}} \times 100 \text {, }
$$

where $P$ is the apparent porosity of the impregnated block and $P_{0}$ is the apparent porosity of the block before impregnation.

The detailed pore properties of the graphite blocks (e.g., pore size distribution) were evaluated using a mercury intrusion porosimeter (AutoPoreV, Micromeritics, GA, USA).

\subsection{Contact Angle Measurement of the Impregnation Pitch for Surface Energy Evaluation}

The surface tension of the impregnation pitch was calculated by dispersing the pitch in tetrahydrofuran and coating it onto polypropylene film; the solvent was then evaporated in the vacuum oven followed by pressing using an auto-press. The contact angles on the prepared pitch film were measured with $10 \mu \mathrm{L}$ of distilled water and diiodomethane using a drop shape analyzer (DSA100, Kruss Scientific, NC, USA).

The pitch contact angle on the graphite block was also measured to assess its wetting behavior on the block. Next, $300 \mathrm{mg}$ of the pitch was placed onto the surface of the block, the temperature was raised to $110^{\circ} \mathrm{C}$, and the contact angle was measured after there was no further change in the melted pitch drop shape, as reported in a previous study [21].

\section{Results and Discussion}

\subsection{Densities and Porosities of the Graphite Blocks before and after Impregnation}

The changes in the bulk densities and open porosities of the graphite blocks before and after impregnation are presented in Table 2. 
Table 2. Bulk densities and open porosities of graphite block before and after impregnation.

\begin{tabular}{ccccc}
\hline \multirow{2}{*}{$\begin{array}{c}\text { Pressure } \\
\text { (bar) }\end{array}$} & \multicolumn{2}{c}{ Bulk Density $\left(\mathbf{g} / \mathrm{cm}^{\mathbf{3}}\right)$} & \multicolumn{2}{c}{ Porosity (\%) } \\
\cline { 2 - 5 } & Unimpregnated & Impregnated & Unimpregnated & Impregnated \\
\hline 10 & 1.763 & 1.798 & 13.95 & 11.84 \\
\hline 20 & 1.762 & 1.796 & 14.12 & 11.84 \\
\hline 30 & 1.760 & 1.798 & 13.93 & 11.30 \\
\hline 40 & 1.760 & 1.801 & 13.93 & 10.71 \\
\hline 50 & 1.761 & 1.804 & 13.69 & 10.34 \\
\hline
\end{tabular}

The bulk densities of the graphite blocks increased to $1.80 \mathrm{~g} / \mathrm{cm}^{3}$ from $1.76 \mathrm{~g} / \mathrm{cm}^{3}$, and their porosities decreased to $10.34 \%$ from $14.12 \%$. However, the densities and porosities of the blocks before impregnation differed slightly_it was difficult to compare the impregnation of each block. Figure 2 depicts the rate of the density increase and impregnation rate of the impregnated blocks with various impregnation pressures from 10 to 50 bar. The density rate increased significantly at impregnation pressures of 40 and 50 bar, whereas the impregnation rate gradually increased as the impregnation pressure increased. When the impregnation pressures were 40 and 50 bar, the impregnation rate significantly increased.
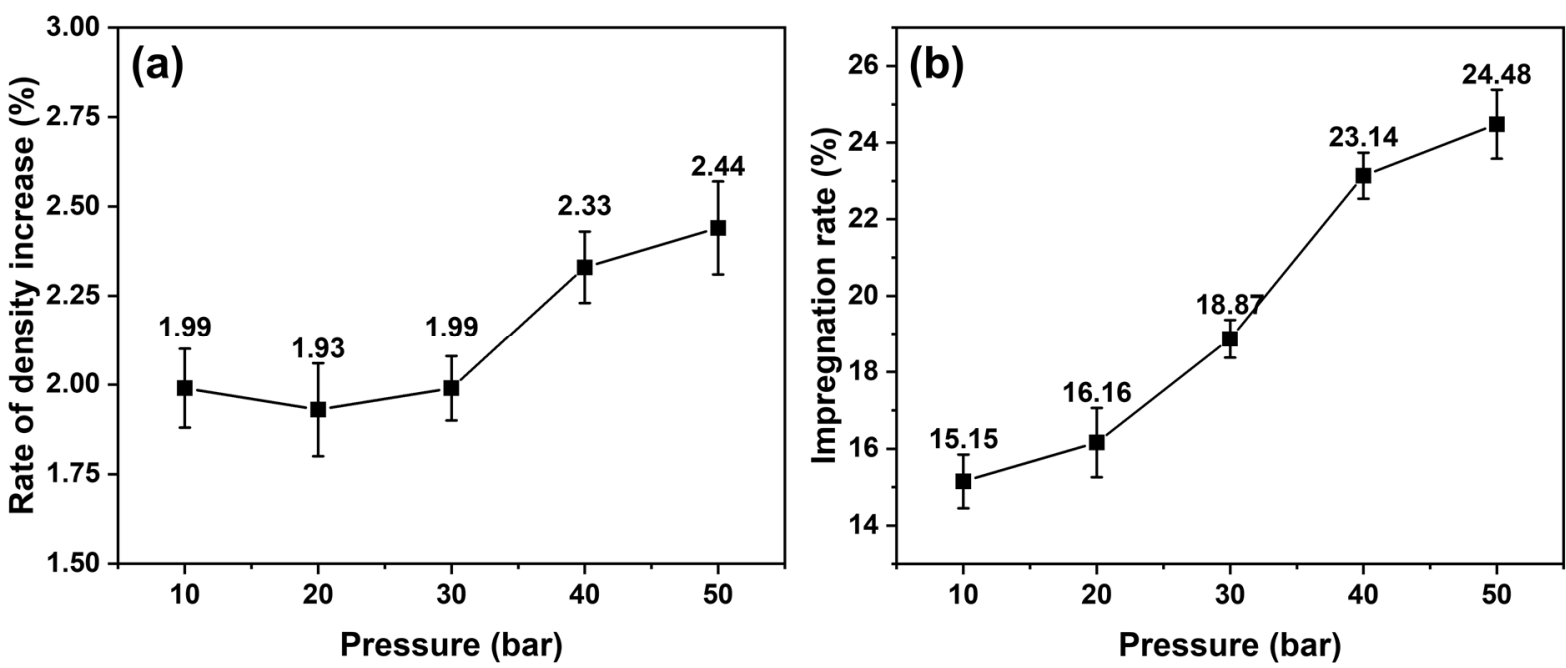

Figure 2. (a) Density rate increase and (b) impregnation rate of impregnated graphite blocks at various impregnation pressures.

As described previously, a portion of the impregnated pitch can be evaporated upon heating for carbonization, and the impregnated pitch melts during carbonization. These two phenomena usually cause the elution of the impregnated pitch, resulting in a reduction in the effectiveness of the pitch impregnation. The higher impregnation pressures of 40 and 50 bar resulted in less elution of the impregnated pitch. The cause of the reduced pitch elution from the graphite blocks is discussed in later sections.

\subsection{Calculation of Minimum Impregnatable Pore Size with Various Impregnation Pressures}

The pitch elution during the carbonization of the impregnated block depends on the pore size of the graphite blocks. When the impregnated pore size of the block is small enough, the impregnated pitch is difficult to elute from the pores. Therefore, the minimum impregnatable pore size at various impregnation pressures is calculated using Washburn's equation, as defined by Equation (2) [22,23].

$$
P=-\frac{4 \gamma \cos \theta}{\delta}
$$


where $P$ is the pressure, $\delta$ is the entrance diameter of impregnated pores, $\gamma$ is the surface tension, and $\theta$ is the contact angle of the impregnator on the graphite block.

In Washburn's equation, the contact angle of the impregnator on the graphite block $(\theta)$ can be directly measured by dropping the melted droplet onto the surface of the block, as described earlier. Moreover, the surface tension of the impregnated pitch $(\gamma)$ can be calculated using the Owens-Wendt equation, as defined by Equation (3) [24,25]. As mentioned in the experimental section, the pitch was formed into a thin film, and the water and diiodomethane contact angles on the pitch film were measured five times. The surface tension of the pitch could then be calculated based on the contact angles.

$$
\gamma_{L}(1+\cos \theta)=2\left(\gamma_{S}^{D} \gamma_{L}^{D}\right)^{1 / 2}+2\left(\gamma_{S}^{P} \gamma_{L}^{P}\right)^{1 / 2}
$$

where $\gamma_{L}$ is the surface tension of the liquid-gas interface, $\theta$ is the liquid contact angle on the pitch film, $\gamma_{S}^{D}$ is the dispersive part of the solid surface tension, $\gamma_{L}^{D}$ is the dispersive part of the liquid surface tension, $\gamma_{S}^{P}$ is the polar part of the solid surface tension, and $\gamma_{L}^{P}$ is the polar part of the liquid surface tension.

Figure 3 depicts the contact angle measurement results for calculating the minimum impregnatable pore sizes under various impregnation pressures. The average water contact angle on the pitch film was $64.1 \pm 7.5^{\circ}$, and the average diiodomethane contact angle on the pitch film was $20.9 \pm 4.0^{\circ}$. These contact angles were used to calculate the surface tension of the impregnating pitch of $47-53$ dyne $/ \mathrm{cm}$. The impregnating pitch contact angle on the graphite block was measured as $133.9 \pm 2.7^{\circ}$. With this surface tension and pitch contact angle, the minimum impregnatable pore size ranges of the graphite block at various impregnation pressures were calculated, as depicted in Figure 4 . When the impregnation pressures were 10,20,30,40, and 50 bar, the impregnatable pores decreased to 120-150, 60-79, 40-53, 30-39, and 24-31 nm, respectively. The small pores impregnated with the pitch are expected to exhibit less elution of the impregnated pitch, possibly explaining why the higher impregnation pressures, 40 and 50 bar, resulted in less elution.

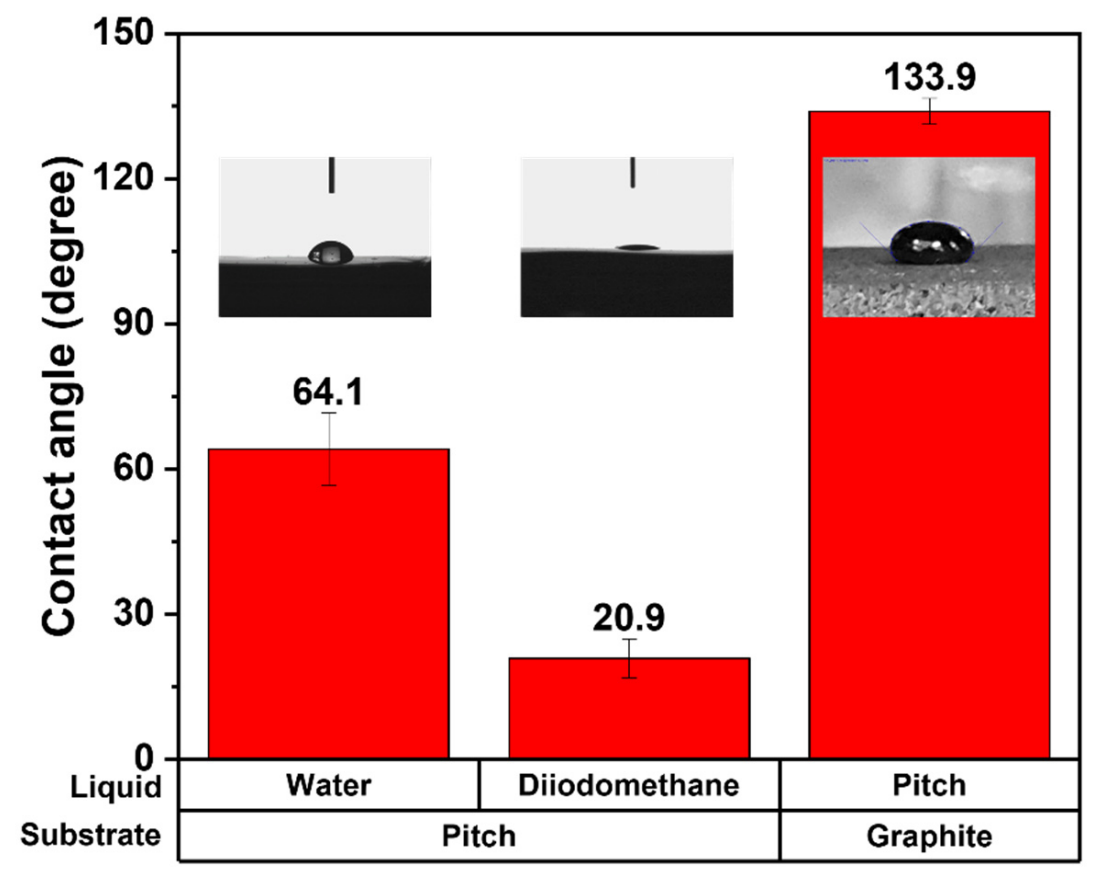

Figure 3. Contact angle measurement results for calculating minimum impregnatable pore sizes under various impregnation pressures. 


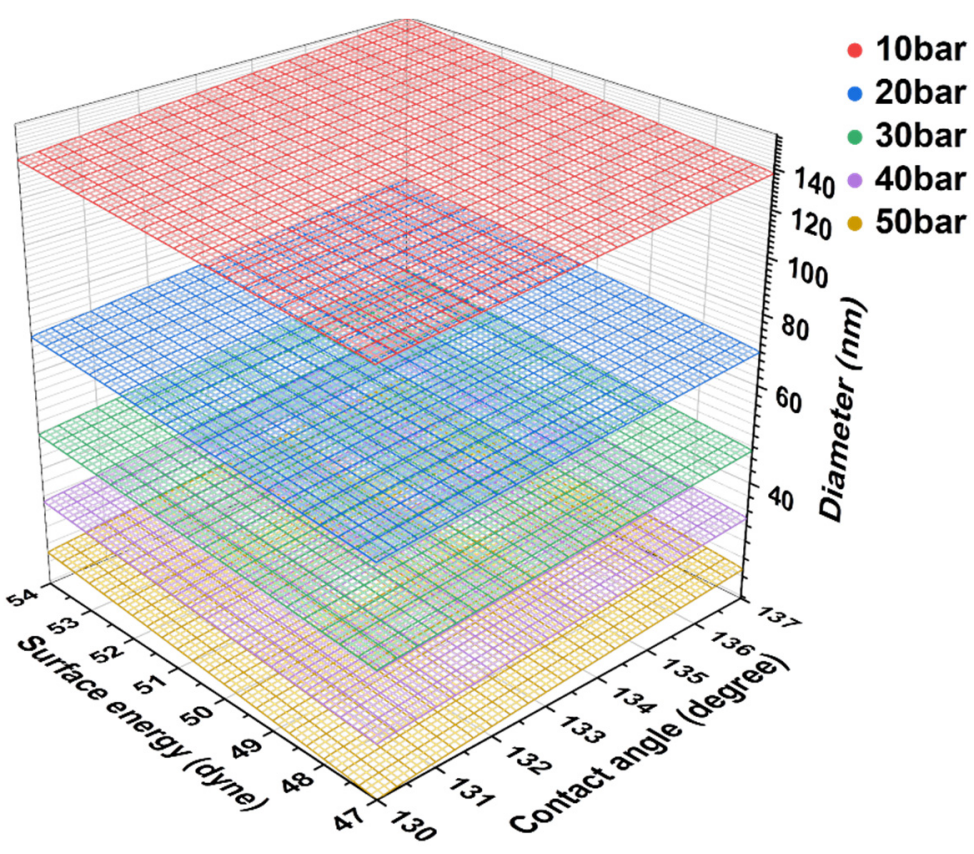

Figure 4. Calculated minimum impregnatable pore size ranges of the graphite block at various impregnation pressures.

\subsection{Pore Properties of Graphite Blocks before and after Impregnation}

The pores of the graphite blocks before and after impregnation at various pressures were observed using a scanning electron microscope (SEM); the images are illustrated in Figure 5. The large pores, with diameters more than $400 \mu \mathrm{m}$, of pristine block disappear after impregnation. By contrast, no significant differences in the other pores of the graphite blocks occur, even after impregnation at various pressures.

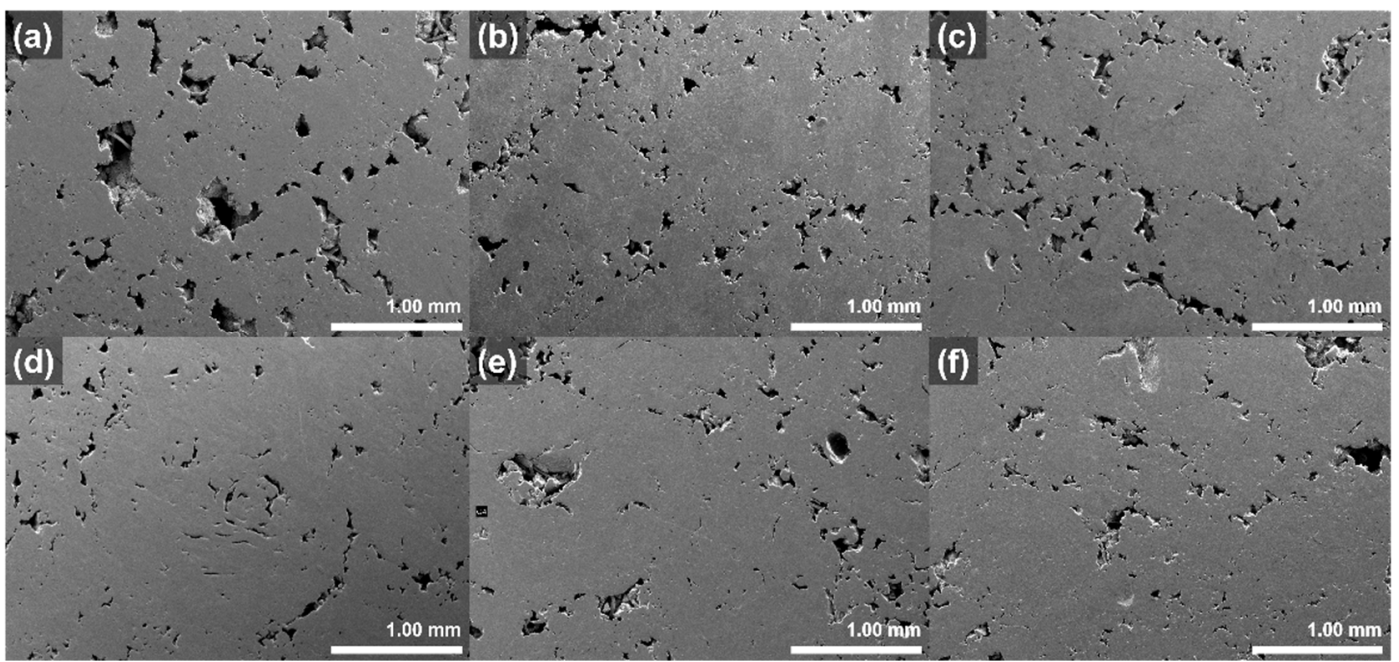

Figure 5. SEM images of graphite blocks before and after impregnation at various pressures: (a) pristine, (b) 10 bar, (c) 20 bar, (d) 30 bar, (e) 40 bar, and (f) 50 bar.

Therefore, a mercury intrusion porosimetry analysis was conducted to investigate the pore properties of the graphite blocks before and after impregnation at various pressures more precisely. The results are depicted in Figure 6. 

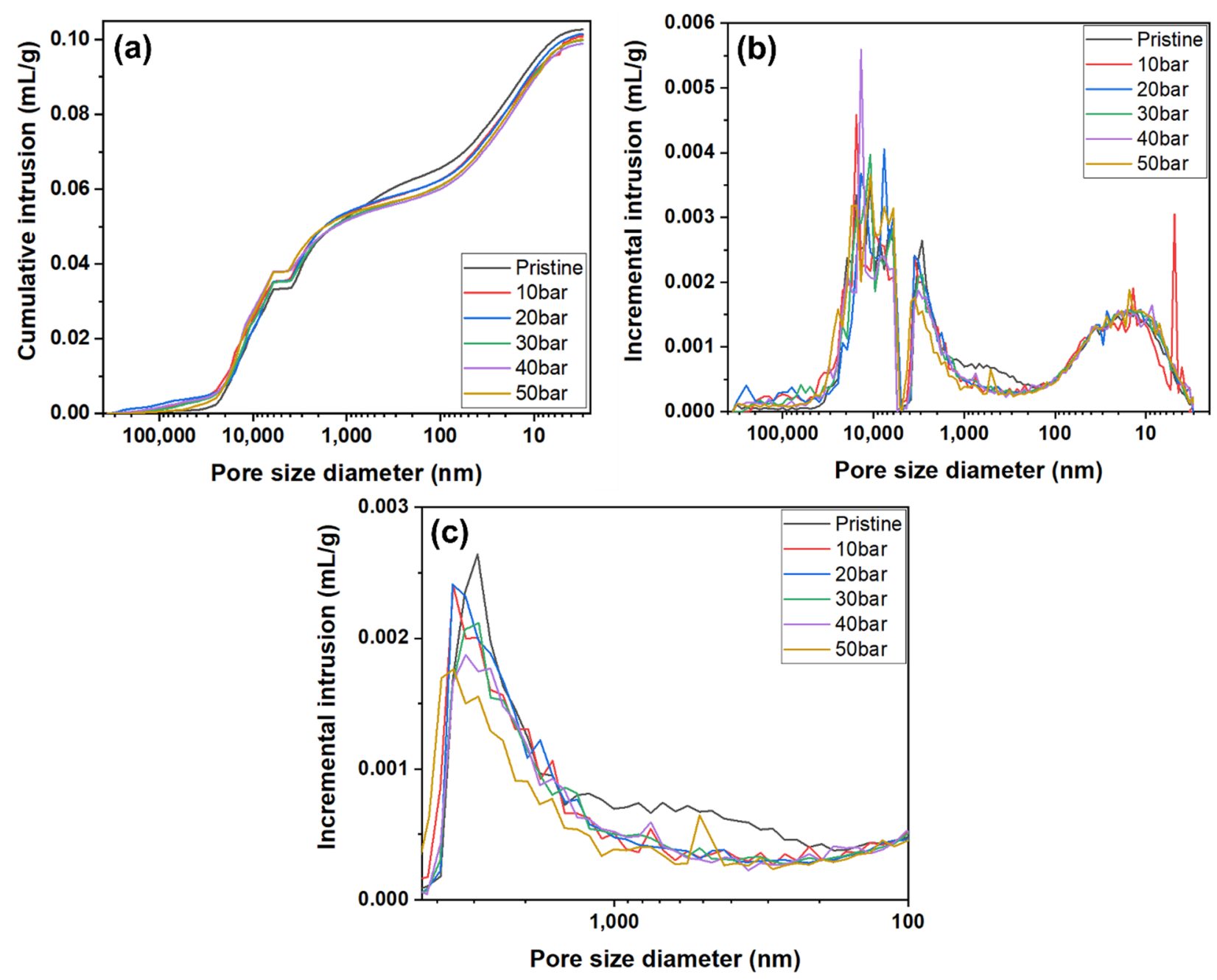

Figure 6. Mercury intrusion porosimetry curves of graphite blocks before and after impregnation at various pressures: (a) cumulative intrusion, (b) incremental intrusion in range of pore size diameter $360,000 \mathrm{~nm}$ to $3 \mathrm{~nm}$, and (c) expansion of the incremental intrusion in range of pore size diameter $4500 \mathrm{~nm}$ to $100 \mathrm{~nm}$.

As depicted in Figure 6a,b, no significant relationship between impregnation pressures and pore size was observed in the large-size pore range of 4500 to $360,000 \mathrm{~nm}$. This may be attributed to the damage of the sample that occurred during sample cutting. The small pore size range of 3 to $100 \mathrm{~nm}$ also did not reveal any significant relationship between impregnation pressures and pore size. However, a significant decrease after impregnation in the pore volume of the pore size range of 100 to $4500 \mathrm{~nm}$ was observed, as depicted in Figure $6 b, c$.

Figure 7 depicts the pore size distributions of the graphite blocks before and after impregnation at various pressures. The pore volumes of the pore sizes in the range of 4500 to $360,000 \mathrm{~nm}$ increased after impregnation due to the damage to the graphite block samples used in the analyses. Graphitized materials are usually harder than carbonized materials; only carbonization was conducted after the impregnation of the graphite blocks. Therefore, the impregnated blocks featured more weak carbonized parts than the pristine graphite block, resulting in more damage to the impregnated block during the sample preparation.

The pore volumes of the pore sizes in the range of 100 to $4500 \mathrm{~nm}$ decreased after impregnation. The relationship between pore volume decrease and impregnation pressure displayed the same trend, as confirmed by the impregnation rates under various pressures. The pore volume with this range significantly decreased after impregnation at 40 and 50 bar. 
However, the pore volume of pore sizes in the range of 3-100 $\mathrm{nm}$ slightly increased after impregnation. Recall from the Washburn's equation results that when the impregnation pressure is $50 \mathrm{bar}$, the pores with a size of $24-31 \mathrm{~nm}$ can be filled with the impregnating pitch. However, the results depicted in Figure 7 exhibited a slight increase in this pore size range because the thermal contraction of the impregnated pitch occurred during carbonization, resulting in a small amount of mesopore formation.

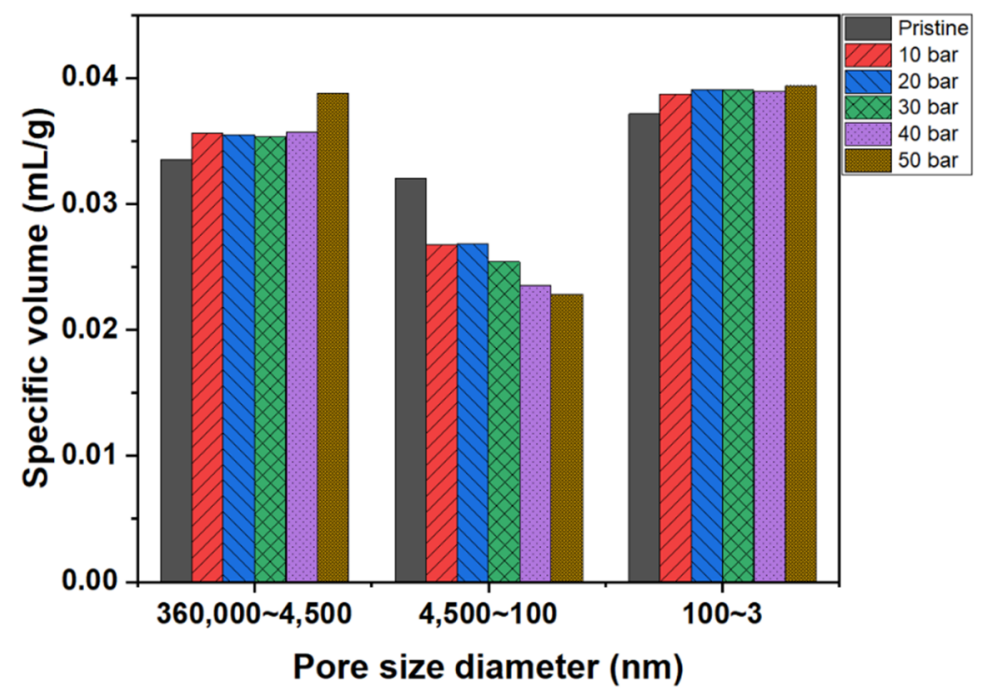

Figure 7. Pore size distributions of graphite blocks before and after impregnation at various pressures.

Figure 8 depicts the mercury intrusion and extrusion curves of the graphite blocks before and after impregnation at various pressures. The hysteresis between mercury intrusion and extrusion is depicted in Figure 8. It is attributed to the presence of ink-bottletype pores, where the mercury cannot be extruded even after lowering the pressure back to the atmospheric pressure. As depicted in Figure 7, the predominant pore size range impregnated with the pitch was $100-4500 \mathrm{~nm}$. Accordingly, the pitch impregnated into the $100-4500 \mathrm{~nm}$ pores was not eluted even after carbonization - it is often difficult to elute impregnated ink-bottle-type pores.

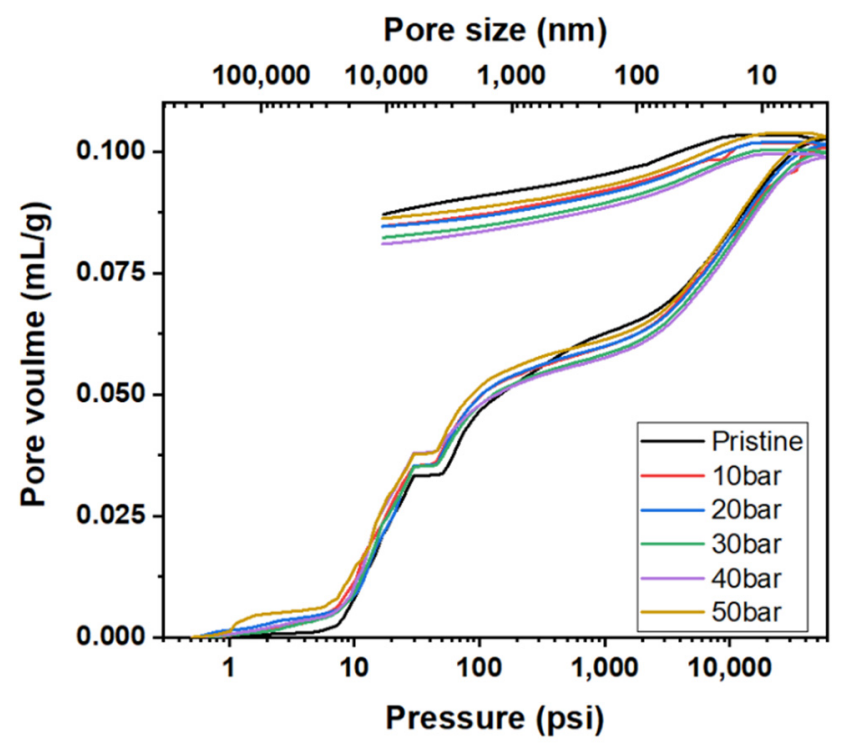

Figure 8. Mercury intrusion and extrusion curves of graphite blocks before and after impregnation at various pressures. 
Table 3 presents the pore volumes and ink bottle fractions of the graphite blocks before and after impregnation. Approximately $64 \%$ of the pores of the pristine graphite block were ink-bottle-type. Moreover, the decreases in these ink-bottle-type pore volumes were $1.17-5.87 \%$. Given that the decreases in the porosities of the impregnated blocks were $2.11-3.35 \%$, the impregnation of the ink-bottle-type pores with the impregnating pitch likely caused them to be filled with pitch without elution during carbonization because they can be narrowed enough to hold the pitch, as depicted in Figure 9.

Table 3. Pore volumes and ink bottle fractions of the graphite blocks before and after impregnation.

\begin{tabular}{cccc}
\hline $\begin{array}{c}\text { Impregnation } \\
\text { Pressure } \\
\text { (bar) }\end{array}$ & $\begin{array}{c}\text { Total Pore Volume } \\
(\mathbf{m L} / \mathbf{g})\end{array}$ & $\begin{array}{c}\text { Ink Bottle } \\
\text { Pore Volume } \\
(\mathbf{m L} / \mathbf{g})\end{array}$ & $\begin{array}{c}\text { Ink Bottle Pore } \\
\text { Fraction } \\
(\mathbf{\%})\end{array}$ \\
\hline pristine & 0.10269 & 0.06573 & 64.01 \\
\hline 10 & 0.10138 & 0.06371 & 62.84 \\
\hline 20 & 0.10114 & 0.06140 & 60.95 \\
\hline 30 & 0.09973 & 0.05907 & 59.23 \\
\hline 40 & 0.09760 & 0.05493 & 59.10 \\
\hline 50 & 0.09997 & 0.05992 & 58.14 \\
\hline
\end{tabular}

impregnation carbonization

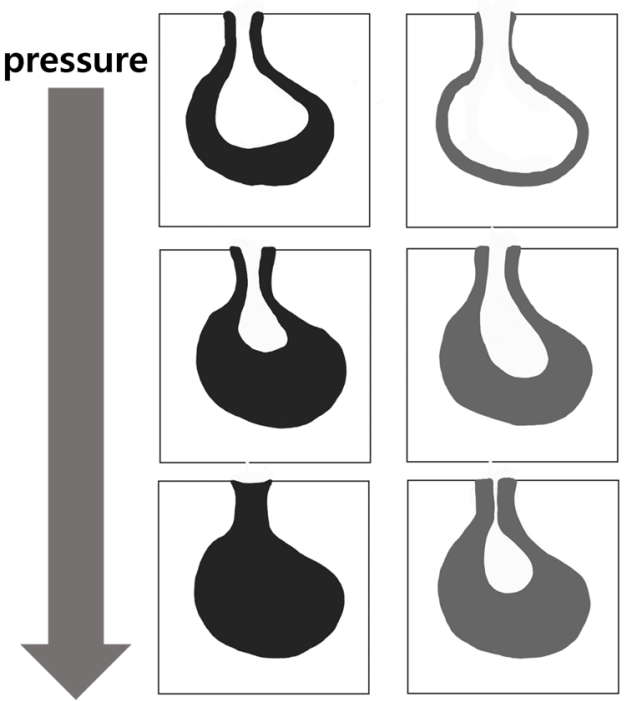

Figure 9. Suggested mechanism of less-impregnated pitch elution from ink-bottle-type pore.

\section{Conclusions}

Bulk graphite blocks with a bulk density of $1.76 \mathrm{~g} / \mathrm{cm}^{3}$ were impregnated with pitch under pressures of 10,20,30,40, and 50 bar. The density density increase rates increased by $1.93-2.44 \%$, whereas the impregnation rate calculated from the rate of open porosity decreased by $15.15-24.48 \%$. The density increase rate and impregnation rate were significantly high when the impregnation pressures were 40 and 50 bar. Compared with impregnation pressures of 10,20, and 30 bar, the minimum impregnatable pore sizes with impregnation pressures of 40 and 50 bar were 30-39 and 24-31 nm, respectively. The mercury intrusion porosimeter analysis results demonstrated that the pressure-sensitive pore size ranges of the graphite blocks were 100-4500 nm. The ink-bottle-type pores in this range contributed the most to the effect of impregnation under pressure because the pitch-impregnated-into-ink-bottle-type pores were difficult to elute during carbonization. 


\begin{abstract}
Author Contributions: Conceptualization, E.J.; methodology, C.K. and W.K.; validation, C.K. and M.H.L.; formal analysis, E.J. and J.S.W.; investigation, C.K. and W.K.; data curation, C.K.; writingoriginal draft preparation, C.K. and E.J.; writing-review and editing, E.J.; visualization, M.H.L. and J.S.W.; supervision, E.J.; project administration, E.J.; funding acquisition, E.J. All authors have read and agreed to the published version of the manuscript.
\end{abstract}

Funding: This work was supported by the Technology Innovation Program (20006696, Development of isotropic graphite block for semiconductor process) funded By the Ministry of Trade, Industry and Energy (MOTIE, Korea).

Institutional Review Board Statement: Not applicable.

Informed Consent Statement: Not applicable.

Data Availability Statement: The data presented in this study are available on request from the corresponding author.

Conflicts of Interest: The authors declare no conflict of interest.

\title{
References
}

1. Gao, Q.; Jin, S.L.; Guo, C.T.; Zhang, R.; Jin, M.L. Effects of Heat-Treatment Temperature and Binder Content on the Microstructure and Thermal Conductivity of Graphite Flake-Carbon Composites. Fuller Nanotub. Car. Nanostruct. 2015, 23, 1043-1050. [CrossRef]

2. Liu, Z.J.; Guo, Q.Q.; Shi, J.L.; Zhai, G.T.; Liu, L. Graphite blocks with high thermal conductivity derived from natural graphite flake. Carbon 2008, 46, 414-421. [CrossRef]

3. Lee, S.-M.; Lee, S.-H.; Kang, D.-S.; Roh, J.-S. A Study on the Possibility of Bulk Graphite Manufacturing using Coal Tar as a Binder and an Impregnant. Compos. Res. 2021, 34, 51-56.

4. Zhou, X.-w.; Tang, Y.-p.; Lu, Z.-m.; Zhang, J.; Liu, B. Nuclear graphite for high temperature gas-cooled reactors. New Carbon Mater. 2017, 32, 193-204.

5. Cho, K.-Y.; Kim, K.-J.; Lim, Y.-S.; Chung, Y.-J.; Chi, S.-H. Specimen geometry effects on oxidation behavior of nuclear graphite. Carbon Lett. 2006, 7, 196-200.

6. Fan, C.-l.; He, H.; Zhang, K.-h.; Han, S.-c. Structural developments of artificial graphite scraps in further graphitization and its relationships with discharge capacity. Electrochim. Acta 2012, 75, 311-315. [CrossRef]

7. Higgins, D.; Zamani, P.; Yu, A.; Chen, Z. The application of graphene and its composites in oxygen reduction electrocatalysis: A perspective and review of recent progress. Energy Environ. Sci. 2016, 9, 357-390. [CrossRef]

8. Prekodravac, J.; Kepic, D.; Colmenares, J.C.; Giannakoudakis, D.A.; Jovanovic, S.P. A comprehensive review on selected graphene synthesis methods: From electrochemical exfoliation through rapid thermal annealing towards biomass pyrolysis. J. Mater. Chem. C 2021. [CrossRef]

9. Kamedulski, P.; Lukaszewicz, J.P.; Witczak, L.; Szroeder, P.; Ziolkowski, P. The Importance of Structural Factors for the Electrochemical Performance of Graphene/Carbon Nanotube/Melamine Powders towards the Catalytic Activity of Oxygen Reduction Reaction. Materials 2021, 14, 2448. [CrossRef] [PubMed]

10. Lee, S.-M.; Kang, D.-S.; Roh, J.-S. Bulk graphite: Materials and manufacturing process. Carbon Lett. 2015, 16, 135-146. [CrossRef]

11. Inagaki, M.; Kang, F. Materials Science and Engineering of Carbon: Fundamentals, 2nd ed.; Elsevier: Waltham, MA, USA, 2014; pp. 382-402.

12. Ragan, S.; Marsh, H. Science and technology of graphite manufacture. J. Mater. Sci. 1983, 18, 3161-3176. [CrossRef]

13. Lee, S.-M.; Kang, D.-S.; Kim, H.-S.; Roh, J.-S. Changes in the porosity of bulk graphite according to the viscosity of resin for impregnation. Carbon Lett. 2015, 16, 132-134. [CrossRef]

14. Lee, S.-M.; Lee, S.-H.; Roh, J.-S. Effect of Change in Open Porosity as a Function of Uniaxial Molding Pressure on Density Improvement After Impregnation. J. Korean Powder Metall. Inst. 2021, 28, 7-12. [CrossRef]

15. Cho, J.H.; Hwang, H.I.; Kim, J.H.; Lee, Y.-S.; Im, J.S.; Kang, S.C. Effect of Coal Tar Pitch Viscosity on Impregnation for Manufacture of Carbon Blocks with High Density. Appl. Chem. Eng. 2021, 32, 569-573.

16. Youm, H.-N.; Kim, K.-J.; Lee, J.-M.; Chung, Y.-J. Effects of impregnation on the manufacture of high-density carbon materials. Yoop Hakhoechi 1993, 30, 852-858.

17. Lahaye, J.; Aubert, J.-P.; Buscailhon, A. Interaction between a coke and a tar. 2. Limit of tar penetration in coke porosity. Fuel 1977, 56, 188-191. [CrossRef]

18. Li, K.; Shen, K.; Huang, Z.-H.; Shen, W.; Yang, G.; Yang, J.; Kang, F. Wettability of natural microcrystalline graphite filler with pitch in isotropic graphite preparation. Fuel 2016, 180, 743-748. [CrossRef]

19. Matzinos, P.; Patrick, J.; Walker, A. Coal-tar pitch as a matrix precursor for 2-DC/C composites. Carbon 1996, 34, 639-644. [CrossRef]

20. ASTM C20-00; Standard Test Methods for Apparent Porosity, Water Absorption, Apparent Specific Gravity, and Bulk Density of Burned Refractory Brick and Shapes by Boiling Water. ASTM International: West Conshohocken, PA, USA, 2015. 
21. Kim, K.H.; An, D.; Kim, J.W.; Lee, Y.-S. The Effect of Fluorination on Wettability between Cokes and Binder Pitch for Carbon Block with High Density. Appl. Chem. Eng. 2018, 29, 677-681.

22. Xu, H.-X.; Lin, J.; Zhong, Y.-J.; Zhu, Z.-Y.; Chen, Y.; Liu, J.-D.; Ye, B.-J. Characterization of molten 2LiF-BeF 2 salt impregnated into graphite matrix of fuel elements for thorium molten salt reactor. Nucl. Sci. Tech. 2019, 30, 74. [CrossRef]

23. Washburn, E.W. The dynamics of capillary flow. Phys. Rev. 1921, 17, 273. [CrossRef]

24. Owens, D.K.; Wendt, R. Estimation of the surface free energy of polymers. J. Appl. Polym. Sci. 1969, 13, 1741-1747. [CrossRef]

25. Lee, Y.-S.; Lee, B.-K. Surface properties of oxyfluorinated PAN-based carbon fibers. Carbon 2002, 40, 2461-2468. [CrossRef] 